\title{
SciBX
}

\section{Science-Business eXchange}

\section{This week in techniques}

Approach
Drug platforms
Zinc finger nuclease-
and piggyBac-mediated
gene correction in
human induced
pluripotent stem (iPS)
cells for gene therapy

Summary

In vitro and mouse studies suggest targeted gene correction in human iPS cells could be used for gene therapy to treat monogenic diseases. In cultured human iPS cells from individuals with $\alpha_{1}$-antitrypsin (AAT; $\mathrm{A}_{1}$ AT; SERPINA1) deficiency, zinc finger nucleases and DNA piggyBac transposons corrected the $A_{1} A T$ point mutation without leaving any extra genetic sequences at the correction site. In hepatocyte-like cells derived from the corrected human iPS cells, genetic abnormalities and mutant $\mathrm{A}_{1}$ AT secretion were absent, and wild-type $\mathrm{A}_{1}$ AT secretion and function was restored. In mice, the iPS cell-derived human hepatocyte-like cells colonized the liver, and there was no tumor formation. Next steps include scaling up the production of corrected iPS cells.

Sangamo BioSciences Inc. has zinc finger nuclease-based compounds in clinical and preclinical testing for multiple indications.

SciBX(42); doi:10.1038/scibx.2011.1194

Published online Oct. 27, 2011
Publication and contact

Licensing status information

Patent and licensing Yusa, K. et al. Nature;

status undisclosed

published online Oct. 12, 2011; doi:10.1038/nature10424

Contact: Allan Bradley, Wellcome

Trust Sanger Institute, Hinxton, U.K. e-mail:

abradley@sanger.ac.uk 